\title{
A TRIGONOMETRICAL IDENTITY
}

\author{
JOHN A. EWELL \\ Department of Mathematical Sciences \\ Northern Illinois University \\ DeKalb, Illinois 60115
}

(Received September 4, 1990)

1. INTRODUCTION. The object of this note is to establish the following identity:

$$
\begin{aligned}
& \left\{(1 / 4) \cot (\theta / 2)+\sum_{k=1}^{\infty} \frac{x^{2 k} \sin k \theta}{1-x^{2 k}}-\frac{1}{2} \sum_{k=1}^{\infty} \frac{x^{k} \sin (k \theta / 2)}{1-x^{2 k}}\right\}^{2} \\
& =\{(1 / 4) \cot (\theta / 2)\}^{2}-\frac{3}{4} \sum_{k=1}^{\infty} \frac{x^{2 k} \cos k \theta}{\left(1-x^{2 k}\right)^{2}}+\frac{1}{8} \sum_{k=1}^{\infty} \frac{k x^{2 k}}{1-x^{2 k}}(3-4 \cos k \theta) \\
& +\frac{1}{8} \sum_{k=1}^{\infty} \frac{k x^{k} \cos (k \theta / 2)}{1-x^{2 k}}-\frac{3}{8} \sum_{k=1}^{\infty} \frac{x^{k}\left(1+x^{2 k}\right)}{\left(1-x^{2 k}\right)^{2}} \cos (k \theta / 2),
\end{aligned}
$$

valid for $\theta \in \mathbf{R}, x \in \mathbb{C}, \theta$ not an even multiple of $\pi$ and $|x|<1$. The details of the proof are supplied in section 2 . In our concluding remarks we compare (1.1) with a celebrated identity of Ramanujan, and discuss a uniform method which reveals a total of four such trigonometrical identities.

2. PROOF OF IDENTITY (1.1). Our argument is based on the following variant of the quintuple-product identity:

$$
\prod_{1}^{\infty} \frac{\left(1-x^{2 n}\right)\left(1-a^{2} x^{2 n-2}\right)\left(1-a^{-2} x^{2 n}\right)}{\left(1+a x^{2 n-1}\right)\left(1+a^{-1} x^{2 n-1}\right)}=\sum_{-\infty}^{\infty} x^{n(3 n+2)}\left(a^{-3 n}-a^{3 n+2}\right),
$$

valid for $a, x \in \mathbf{C}, a \neq 0$ and $|x|<1$. For a discussion of (1.2) and other forms of the quintupleproduct identity see [1].

In (1.2) let $a \rightarrow-a, x \rightarrow x^{3}$, and multiply the subsequent identity by $-a^{-1} x$ to get

$$
\left(a-a^{-1}\right) x \prod_{1}^{\infty} \frac{\left(1-x^{6 n}\right)\left(1-a^{2} x^{6 n}\right)\left(1-a^{-2} x^{6 n}\right)}{\left(1-a x^{6 n-3}\right)\left(1-a^{-1} x^{6 n-3}\right)}=\sum_{-\infty}^{\infty}(-1)^{n} x^{(3 n+1)^{2}}\left(a^{3 n+1}-a^{-3 n-1}\right) \text {. }
$$


Let $F(a, x)$ denote the left side of the foregoing identity, and for a complex variable $z$, regard $z D_{z}$ as an operator, where $D_{z}$ denotes derivation with respect to $z$. Then,

$$
\begin{aligned}
\left(a D_{a}\right)^{2}\{F(a, x)\} & =\sum_{-\infty}^{\infty}(-1)^{n}(3 n+1)^{2} x^{(3 n+1)^{2}}\left(a^{3 n+1}-a^{-3 n-1}\right) \\
& =\left(x D_{x}\right)\{F(a, x)\} .
\end{aligned}
$$

We now use the technique of logarithmic differentiation to evaluate the leftmost and rightmost members of (2.2), cancel $F(a, x)$ in the resulting identity, and then let $x \rightarrow x^{1 / 3}$ to get

$$
\begin{aligned}
& \left\{\frac{a+a^{-1}}{a-a^{1}}-2 \sum_{k=1}^{\infty} \frac{x^{2 k}}{1-x^{2 k}}\left(a^{2 k}-a^{-2 k}\right)+\sum_{k=1}^{\infty} \frac{x^{k}}{1-x^{2 k}}\left(a^{k}-a^{-k}\right)\right\}^{2} \\
& =1+\frac{4}{\left(a-a^{-1}\right)^{2}}+4 \sum_{k=1}^{\infty} \frac{k x^{2 k}}{1-x^{2 k}}\left(a^{2 k}+a^{-2 k}\right)-\sum_{k=1}^{\infty} \frac{k x^{k}}{1-x^{2 k}}\left(a^{k}+a^{-k}\right) \\
& -6 \sum_{k=1}^{\infty} \frac{k x^{2 k}}{1-x^{2 k}}+6 \sum_{k=1}^{\infty} \frac{x^{2 k}}{\left(1-x^{2 k}\right)^{2}}\left(a^{2 k}+a^{-2 k}\right)+3 \sum_{k=1}^{\infty} \frac{x^{k}\left(1+x^{2 k}\right)}{\left(1-x^{2 k}\right)^{2}}\left(a^{k}+a^{-k}\right) .
\end{aligned}
$$

In the foregoing identity let $a=e^{i \theta / 2}, \theta$ subject to the stated restrictions. We simplify the resulting identity, and finally divide by -16 to arrive at identity (1.1).

CONCLUDING REMARKS. The forerunner of all identities of type (1.1) is a celebrated one due to Ramanujan [2, p. 139], viz.,

$$
\begin{aligned}
& \left\{(1 / 4) \cot (\theta / 2)+\sum_{1}^{\infty} \frac{x^{k} \sin k \theta}{1-x^{k}}\right\}^{2} \\
= & \{(1 / 4) \cot (\theta / 2)\}^{2}+\sum_{1}^{\infty} \frac{x^{k} \cos k \theta}{\left(1-x^{k}\right)^{2}}+\frac{1}{2} \sum_{1}^{\infty} \frac{k x^{k}}{1-x^{k}}(1-\cos k \theta),
\end{aligned}
$$

with the same restrictions on $\theta$ and $x$. Ramanujan himself made substantial applications of his identity to the theory of elliptic modular functions. However, the most familiar application of the identity is perhaps that of Hardy and Wright [3, pp. 311-314]. These authors use the identity to establish Jacobi's formula for the number $r_{4}(n)$ of representations of a natural number $n$ by sums of four squares. Ewell [4] shows that the method of this note permits an easy and straightforward derivation of Ramanujan's identity. Moreover, the method also reveals two additional trigonometrical identities of this type.

\section{REFERENCES}

1. SUBBARAO, M.V. and VIDYASAGAR, M., "On Watson's quintuple-product identity", Proc. Amer. Math. Soc. 26 (1970), 23-27.

2. RAMANUJAN, S., Collected Papers, Chelsea, New York, 1962.

3. HARDY, G.H. and WRIGHT, E.M., An Introduction to the Theory of Numbers, 4th ed., Oxford, (1960).

4. EWELL, J.A., "Consequences of the triple- and quintriple-product identities", Houston $\mathrm{J}$ Math. 14 (1988) 51-55. 


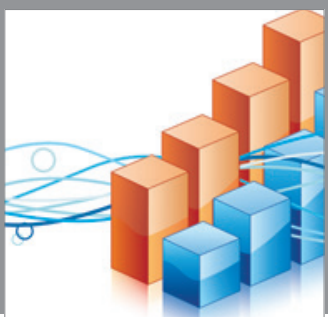

Advances in

Operations Research

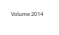

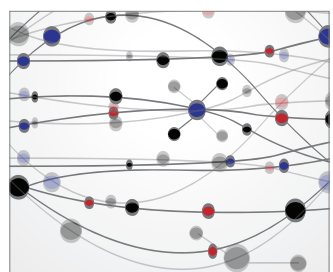

\section{The Scientific} World Journal
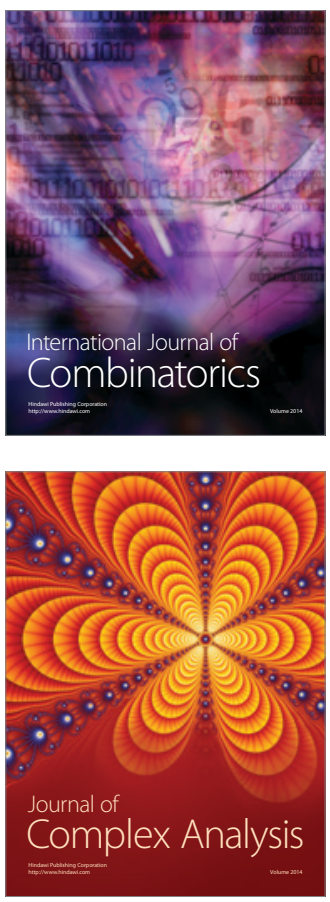

International Journal of

Mathematics and

Mathematical

Sciences
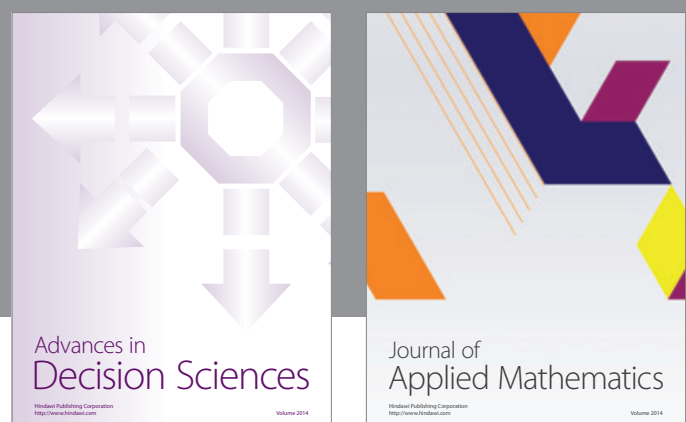

Journal of

Applied Mathematics
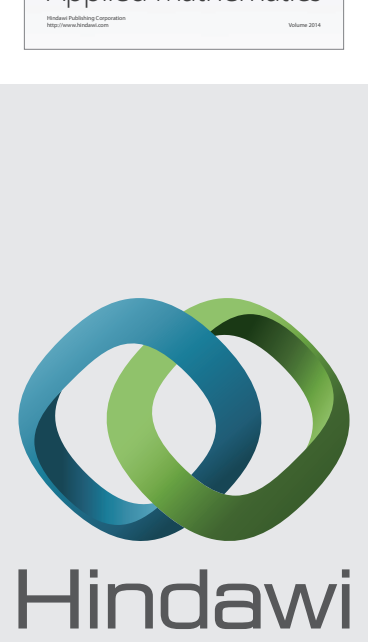

Submit your manuscripts at http://www.hindawi.com
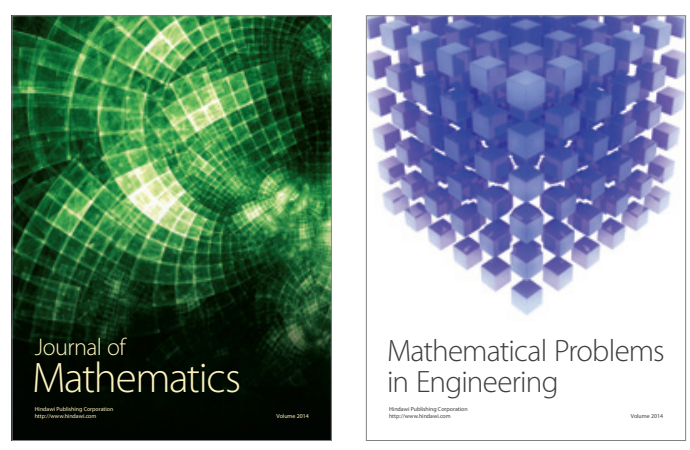

Mathematical Problems in Engineering
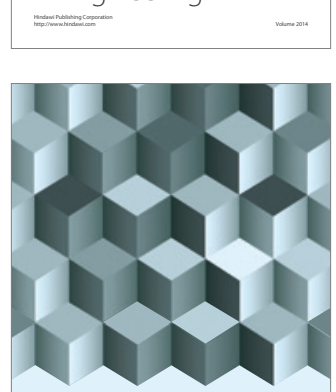

Journal of

Function Spaces
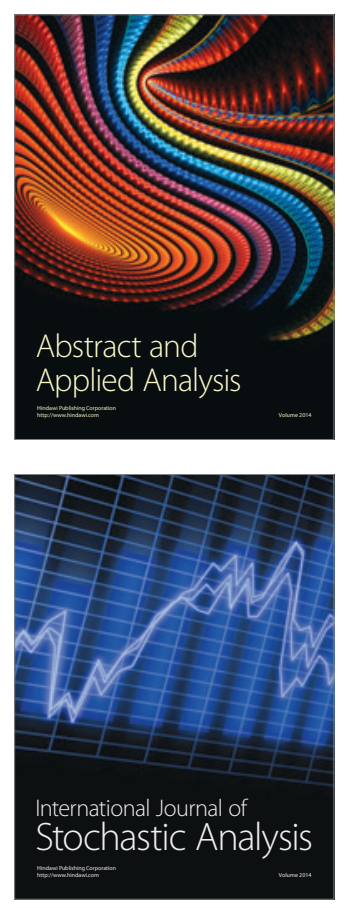

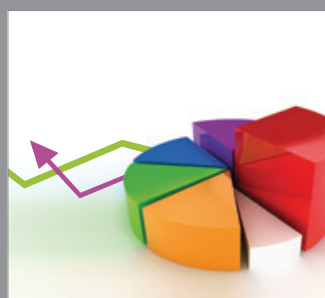

ournal of

Probability and Statistics

Promensencen
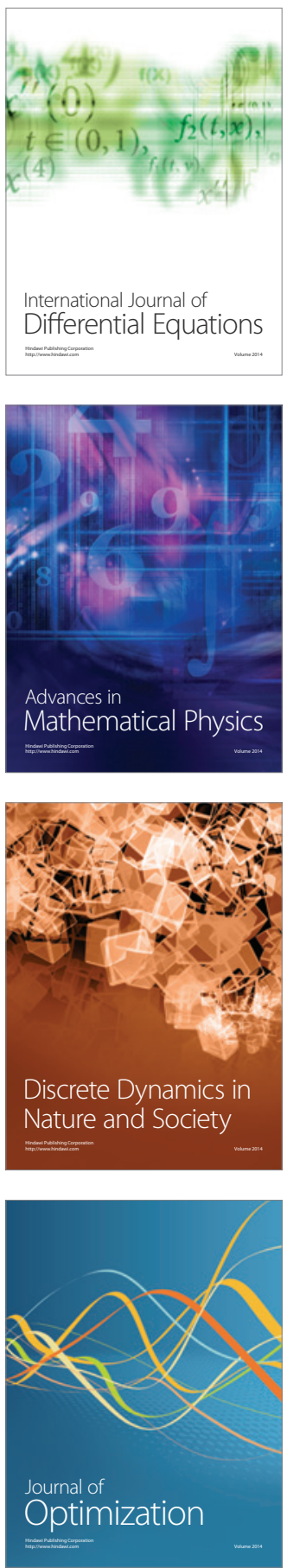